\title{
Nature Conservation and Biodiversity Monitoring through a Spatial Data Infrastructure
}

\author{
Cristina Oana, Cristian Vasile and Simona Ipate (Staiculescu) \\ Esri Romania, Bucharest 011774, Romania
}

\begin{abstract}
One of the main concerns of the European Union environment policy is the deterioration of natural habitats and the threats posed to certain species under the Habitat Directive. With its huge diversity of plant and animal species and high level of endemism, Romania is nominated as a European biodiversity hotspot. Biodiversity is being lost at a dramatic rate unless strategically conservation measurements are taken. Halting the loss of biodiversity is regarded as a priority to the European Member States which are encouraged to work together within the same strong legislative framework in order to protect our most vulnerable species and habitat types. Romania is also in the process of developing the Spatial Data Infrastructure in response to Geographic Information 2000 Initiative launched by the European Commission in 1996 and the INSPIRE (Infrastructure for Spatial Information in Europe) initiative launched in 2001. The focus of this article is the development of the geospatial architecture framework and applications required for efficient inventory and mapping of natural habitats and wild species of community interest. Implementing a biodiversity geoportal application is seen as critical in order to help users share the geospatial information in the environment and sustainable development sectors.
\end{abstract}

Key words: Geoportals, biodiversity, INSPIRE, metadata, standards.

\section{Introduction}

The natural heritage of the Carpathians and Danube basin is highly important for the entire Europe due to its unique flora, fauna, climate and landscape. As many plants and animal species are under pressure due to the habitat fragmentation and excessive exploitation of the natural resources, Romania is considered one of the European countries with the highest number of endangered species.

From the European perspective, Romania has to ensure the establishment of Natura2000 network in accordance to the Birds and Habitats Directives and to prepare important protection measures for the community interest sites. The management of Natura2000 network is closely related to the natural protected areas, therefore an appropriate management and monitoring system has to be developed and implemented for these areas.

Corresponding author: Cristina Oana, Ph.D., research fields: GIS, GPS, Inspire, geospatial standards and biodiversity. E-mail:cov_gps@esriro.ro.
In the context of EU legislation, as a response to the European Union Directives, regarding the reports on biodiversity conservation in all Member States Protected Areas (Article 6, Habitats Directive, 1992; Articles 9 and 12, Birds Directive, 2009), assessing the need for biodiversity information has been addressed by managers of protected areas, scientists, decision makers, researchers and many others. Most of these people involved in work related to protected areas are aware that the absence of reliable spatial information can have the most serious consequences for the understanding of biodiversity and for decision making, which has been accessible to all interested parties and integrated with other relevant information. However, the situation is still critical, because usually the current biodiversity data are available as text documents, although the biodiversity data needed to meet the conservation strategy should be centralized in the form of geospatial databases and shared and disseminated in order to allow interoperability and interconnection between networks. This is where the 
ability of using webGIS and geoportal technologies as a tool to monitor the habitat changes, to track wildlife demographics, to predict future land and resources, to use and share all this results according to the EU policies, is essential to conservation goals and practices.

Directive 2007/2/EC of the European Parliament and of the Council of 14 March 2007 establishing an INSPIRE (Infrastructure for Spatial Information in Europe) entered into force on May 152007 and is operated by the 27 Member States of the European Union. The transposition into the Romanian legislation was January 2010 and was published in the Romanian Official Journal on January 29, 2010-OG ${ }^{1}$ $04 / 2010$. In the context of INSPIRE, an open and transparent process for the national stakeholder participation has been set up. Stakeholders are part of the INIS (National Infrastructure for Spatial Information) Council, which is under the coordination of the National Cadaster Agency and Land Registration as a Legal Mandated Organization in INSPIRE. INIS Council includes 19 organizations which are composed of Technical Working Groups experts for developing the technical specifications for each spatial theme in annexes which they are personally responsible for. Ministry of Environment and Climate Changes plays also a central role as Vice President of the INIS $^{2}$ Council in reviewing and testing the draft implementing rules and in assessing their potential impact in respects to both costs and benefits.

To accomplish all these goals, we have built a geoportal application which provides added benefits to the management of the natural protected areas and biodiversity decision makers and offers improved data for other projects in this environmental sector and for our National Spatial Data Infrastructure.

\footnotetext{
1 Information can be found on http://eur-lex.europa.eu/LexUriServ/LexUriServ.do?uri=CELE X:72007L0002:EN:NOT\#FIELD_RO.

2 INIS-National Infrastructure for Spatial Information in accordance to OG 04/2010, article 1, section 1.
}

\section{The Challenge}

Europe has established an extensive network of protected areas to help protect endangered species and habitat types. However, widespread alterations of the landscape coupled with degradation of ecosystems have prevented the EU from meeting its target of halting biodiversity loss by 2010. At this moment, it does not exist a standard and uniform information system that would allow us differentiation of the specific conservation measures, monitoring and implementation of the management activities and adjustments of the adaptive management percepts.

Romania's natural capital is important for the European Union due to rich flora and fauna and the climate landscape offered by the Carpathian-Danubian-Pontic area. Romania has a high diversity of flora and fauna. However, there are many species of plants and animals endangered because of habitat fragmentation and overexploitation of natural resources, combined with pressures caused by economic development. Romania's natural capital, due to the biogeographic conditions, still contains a very marked effect of number of species that are classified as rare or endangered in Europe and worldwide.

Developing the management and monitoring framework of the protected areas, and especially Natura2000 sites will trigger several actions, such as the development of the administrative structures, the development/revision of management plans for protected areas, the implementation of specific infrastructure, the preparation of specific scientific studies, inventory, mapping, undertaking special measures to conserve species and natural habitats, information campaigns and public awareness, and other actions.

Unitary systems are developed at the European level in terms of monitoring methodologies and strategies of environment reporting. UK has already developed and implemented a Common Standards Monitoring system to obtain and maintain Favorable 
Conservation Status for all Natura2000 sites. France and Germany have also established the monitoring and reporting schemes without implementation of a standard system. Nevertheless, Romania is in the process of implementing a series of projects belonging to the SOP ENV (Sectorial Operational Program "Environment"), projects that are focused on inventorying and mapping natural habitats and wild species of community interest for the major natural protected areas.

Regarding our technical challenges, very few people understand or use the complexity of the technical documentation of the INSPIRE architecture and implementation of the technical specifications for each spatial theme in annexes which they are responsible for. Even using the guidelines for the creation of metadata files that are compliant both with the INSPIRE Implementing Rules for Metadata as well as with relevant European and international standards for geographic information represents a technical challenge at this moment. The capacity to sustain the training process, technical competencies, consistence of training materials and translation into Romanian language have to be built up by the Ministry of Environment and Climate Changes and national, regional and local authorities and stakeholders. There have been significant efforts in respect to the IT infrastructures to sustain coordination of the INSPIRE activities.

Another important challenge is to maintain a high level of commitment of all targeted user groups: Ministry of Environment and Climate Changes, National, Regional and Local Agency for the environment protection, custodians and other experts to contribute to the development of an appropriate management and monitoring system. This is not trivial and requires a notable amount of expertise, money, time and commitment as resources to ensure a more effective implementation. The difficult financial climate of this period makes it potentially more challenging to support investments in new IT infrastructures, education and training services.

We do consider that our biodiversity geoportal application will act as a foundation for producing, sharing and consuming biodiversity and natural heritage geospatial information, improving decision making and operations with respect to these issues that are affecting also Europe as a whole.

\section{Case Study}

This study focuses on only one of the Romanian protected areas, but could be successfully applied in many other related projects, as it describes a complete solution to collecting, centralizing, analyzing and sharing biodiversity data and new field data in a standardized mode, in order to address biodiversity assessment and monitoring purposes. Based on a webGIS approach, the study outputs a geospatial biodiversity monitoring system, adopted by many protected areas in Romania, which integrates: (1) a centralized database of biodiversity information related to the study area, which supports thematic maps and many other cartographic products; (2) the analysis methodology that allows to assess the key characteristics and the conservation status, which designate the area as protected; and (3) a geoportal application which is ensuring interoperability and expanding the access to biodiversity geospatial data, maps, metadata, web services and applications as part of the Romanian National Spatial Infrastructure. Standardized set of reports, presentations and graphics has been created for each component of the system, based on the Common Monitoring Standards [1].

The site related to this case-study represents a 11.300 ha protected area named Siriu, located in the northern part of Buzau County, in Romania and managed by the Administration of Buzau County Council. The area was officially declared as a protected site, by the order of the Ministry of Environment No. 1964/2007, regarding the declaration of protected sites as integrated part of NATURA2000 European ecological network. 


\section{Biodiversity Geodatabase for ROSCI0229}

Most of the data related to this studied protected area were missing or lacking information and proved to be very challenging also for us. First of all, there is no country that has a comprehensive species list for any of the species-rich groups, and, furthermore, the costs of undertaking the preparation of such a list, which generally requires work from scratch, will generally be prohibitive. Secondly, background data (topographical data) and data needed for the morphometric analysis were missing or were out of date. Data sources that we had to gather fall into the following categories: (1) catalogues covering the literature of entities names including countries of origin and updating issues; (2) checklists and biotas (floras and faunas), which are complementary tools that provide a basis for a full account of species including descriptions and keys; (3) the associations between plants species and habitats; (4) topographic data; (5) administrative data; (6) land cover data; (7) EEA (European Environment Agency) reference grids [2] — with different cell sizes used to mark the presence/absence of species or habitat; (8) soil data; (9) geology data; (10) data needed for morphometric analysis (slope, curvature, aspect, altitude); (11) landsat imagery-used for classification; (12) currently available aerial photo-for feature extraction, and other resources.

The first next step was to gather all the above necessary information, using EEA automation tools where possible (such as importing or loading from different formats to GIS known formats), GIS spatial analysis tools (to create slope, aspect, flow direction, curvature rasters) or just basic GIS data collection tools (to digitize features or manually collect attribute data related to species and habitats). For this purpose, we manually collected the list of species and habitats with specific descriptions, codes and groups or associations, using the Romanian Manual for Interpretation of EU Habitats, and other Natura2000 documentation [3].

The data were sorted according to a type as spatial or non-spatial in a geodatabase structure, designed using ArcGIS software according to the data specifications of INSPIRE Directive-Annex I [4]. The attributes and non-spatial data were associated within the geospatial database as appropriate [5].

The geodatabase schema (Fig. 1) includes the following geospatial themes: land cover, hydrography, morphology, transportation, soils, geology, biodiversity; habitats and species threats areas; field surveys on habitats and species threats, etc.; EEA grid reference system, and non-spatial tables (habitats, species, plants association).

The ROSCI0229 geodatabase schema was properly optimized in order to support all our project workflows. The available data were migrated into the geodatabase schema and using a Microsoft SQL Server
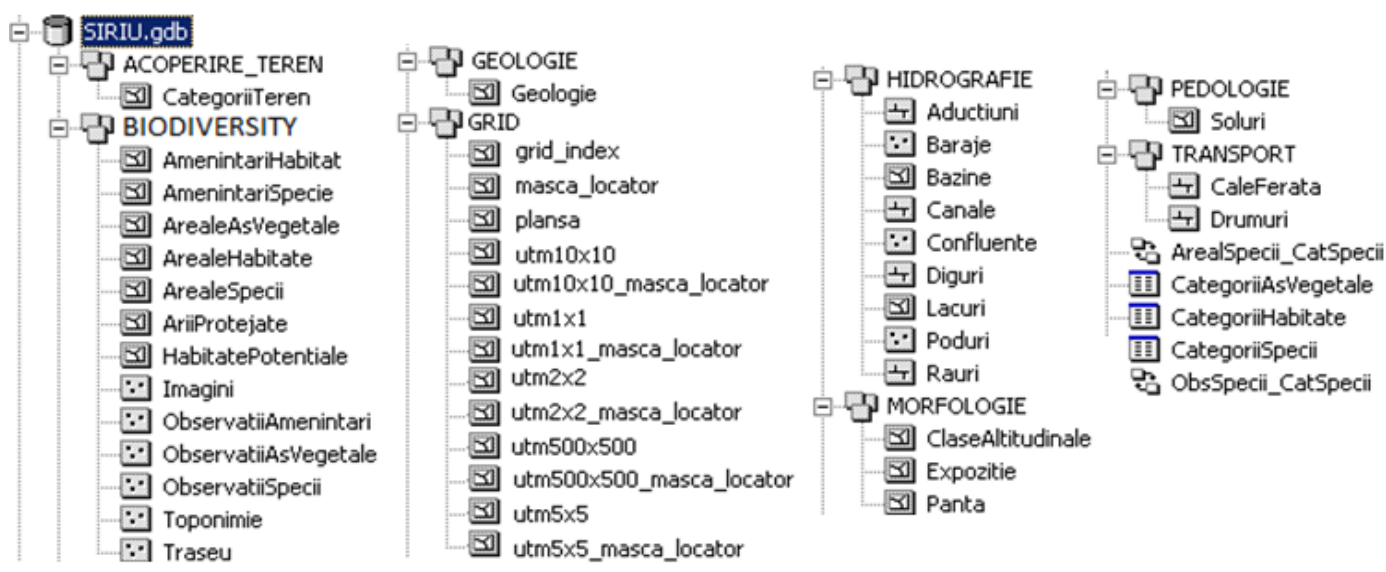

Fig. 1 ROSCI0229 Siriu—biodiversity geodatabase physical model. 
database tied to ArcGIS; a GIS repository was created for the whole studied area, consolidating data from disparate sources and formats. Implementing this enterprise geodatabase is a big step ahead for the evolution of this type of projects, ensuring interoperability and enabling accessibility to other environmental users.

We have implemented some QA/QC (Quality Assurance and Quality Control) mechanisms in order to ensure the accuracy and quality of the existing and acquired data from the field. The QA/QC process included two phases: an automatic data check and a visual data check. The data validation process was successfully passed after a few more field surveys which ensured data accuracy and after the completion of the missing data attributes. After data cleaning and assembling processes, we began to use it for next step of the analysis and modelling in order to be able to extract the information we needed.

\section{Biodiversity GeoPortal}

ROSCI0229 Siriu GeoPortal [6] based on geoportal technology represents the public side of the project, which is available to any user interested in biodiversity, including all geospatial resources obtained in the study. A geoportal, as indicated by the prefix "geo", is a portal that specializes in geospatial information. A geoportal, also referred to as a spatial portal, is a Web site that provides a single point of access to geospatial data, Web services, and other geospatially related resources. Put more simply, a geoportal is a Web site where geospatial resources can be discovered and, eventually, used [7].

\subsection{Geoportal Functions}

The biodiversity geoportal provides functionality to each of the three roles-publisher, administrator and users-associated with it. Publishers provide the content to the geoportal. Administrators manage the content and users can search for contents that meet their specific criteria. The biodiversity geoportal application allows users to perform a search in the following ways:

- Web site [8]: users specify search criteria and review the search results as presented in Fig. 2;

- Programming interfaces: the $\mathrm{REST}^{3}$ interface can return search result in GeoRSS ${ }^{4}, \mathrm{KML}^{5}, \mathrm{HTML}^{6}$, HTML fragments and $\mathrm{JSON}^{7}$ formats;

- Widget: in the geoportal Flex-based Map Viewer [9] users can view, query and explore published resources, and users can locate and explore Natura2000 Romanian monitored sites and biodiversity content results, including: an enterprise geodatabase, available for querying via web, a complex detailed base-map, downloadable distribution maps, survey data, pictures and reports.

\subsection{Geoportal Resources Content}

The ROSCI0229 Siriu biodiversity geoportal incorporates the following:

- Framework datasets-are presented in Fig. 3, including nine themes: topographic base-maps, orthoimagery, elevation, geology, hydrography, transportation, administrative units, protected area

\footnotetext{
${ }^{3}$ REST-acronym for Representational State Transfer. REST interface available in our application allows programs on different computers to communicate independently of an operating system or platform by sending a HTTP (Hypertext Transfer Protocol) request to a URL (uniform resource locator) and getting back data in some format-for example, XML, or inside a URL. REST is used in Web services.

${ }^{4}$ GeoRSS-acronym for Geographically Encoded Objects for RSS feeds. Metadata for RSS documents that describes the location of Web content. The GeoRSS feed of the biodiversity Geoportal is also available to be integrated in Internet Explorer. 5 KML-Keyhole Markup Language is an XML based language schema for expressing geographic annotation and visualization on existing or future Internet-based two-dimensional maps and three-dimensional Earth browsers. The REST API KML of the biodiversity GeoPortal applications is integrated in Google Earth application.

6 HTML (HyperText Markup Language) and HTML FRAGMENT-REST API HTML Fragments of the Biodiversity GeoPortal applications is integrated in JSPWiki.

7 JSON-acronym for JavaScript Object Notation that is a lightweight text-based open standard designed for human-readable data interchange. In our GeoPortal application, the JSON appears at the bottom of the search results on the search page. It is possible to see the list of the results in formatted JSON, called “PJSON” by clicking JSON link.
} 


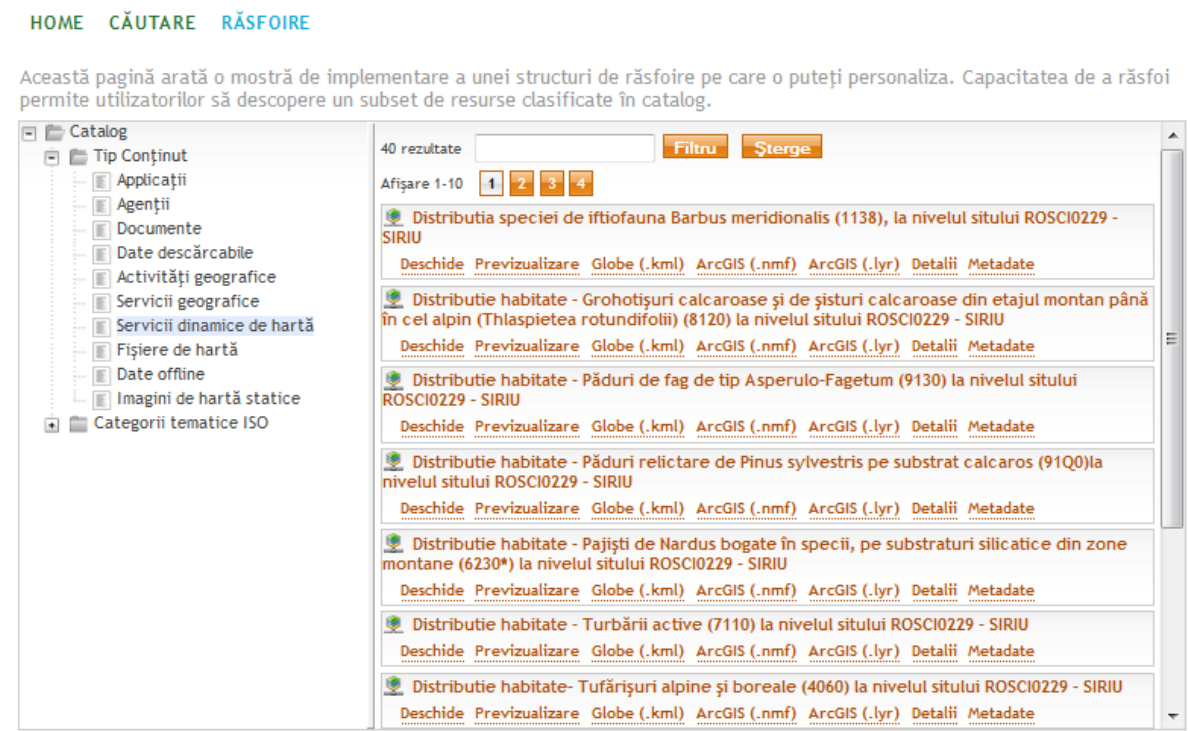

Fig. 2 ROSCI0229 Siriu Geoportal-harvest capability.

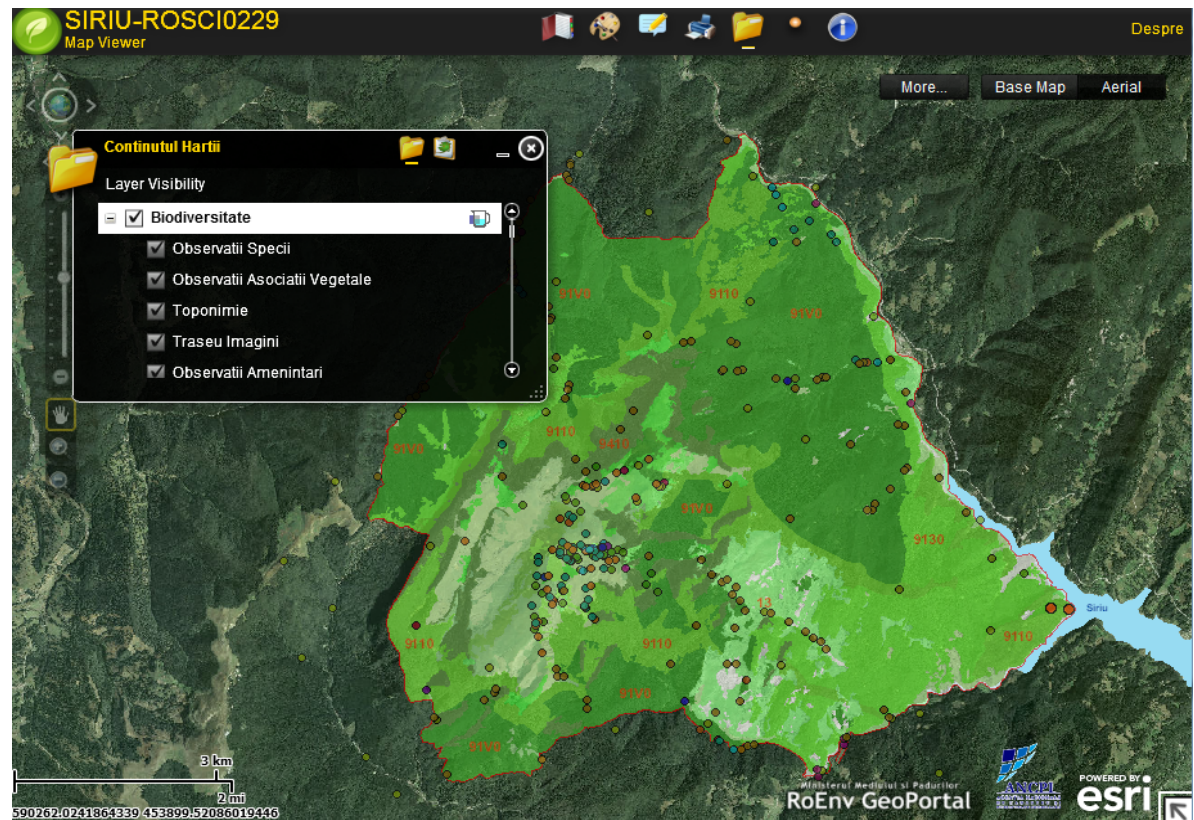

Fig. 3 ROSCI0229 Siriu Geoportal—framework datasets.

sites, and hydrological constructions;

- Operational layers (or thematic layers) presented in Fig. 4-show items of natural habitats and wild species of community interest on top of the base-map in order to monitor the Favorable Conservation status, including: 14 habitats distribution maps, five flora and fauna distribution maps, two animal and fish distribution maps and three of mammals distribution maps [10].

Assessment of the conservation status was determined for each natural habitat in part by describing the degree of conservation of structures and functions and possibilities of recovery/reconstruction. This assessment of the conservation status is different for each wild species, derived by observation of their behavior, appearance analysis, measurements, mortality, comparisons with expert guides, etc..

The qualitative assessment of the measurements includes an exhaustive list of invasive species from the structure of prioritized habitats, while for quantitative 


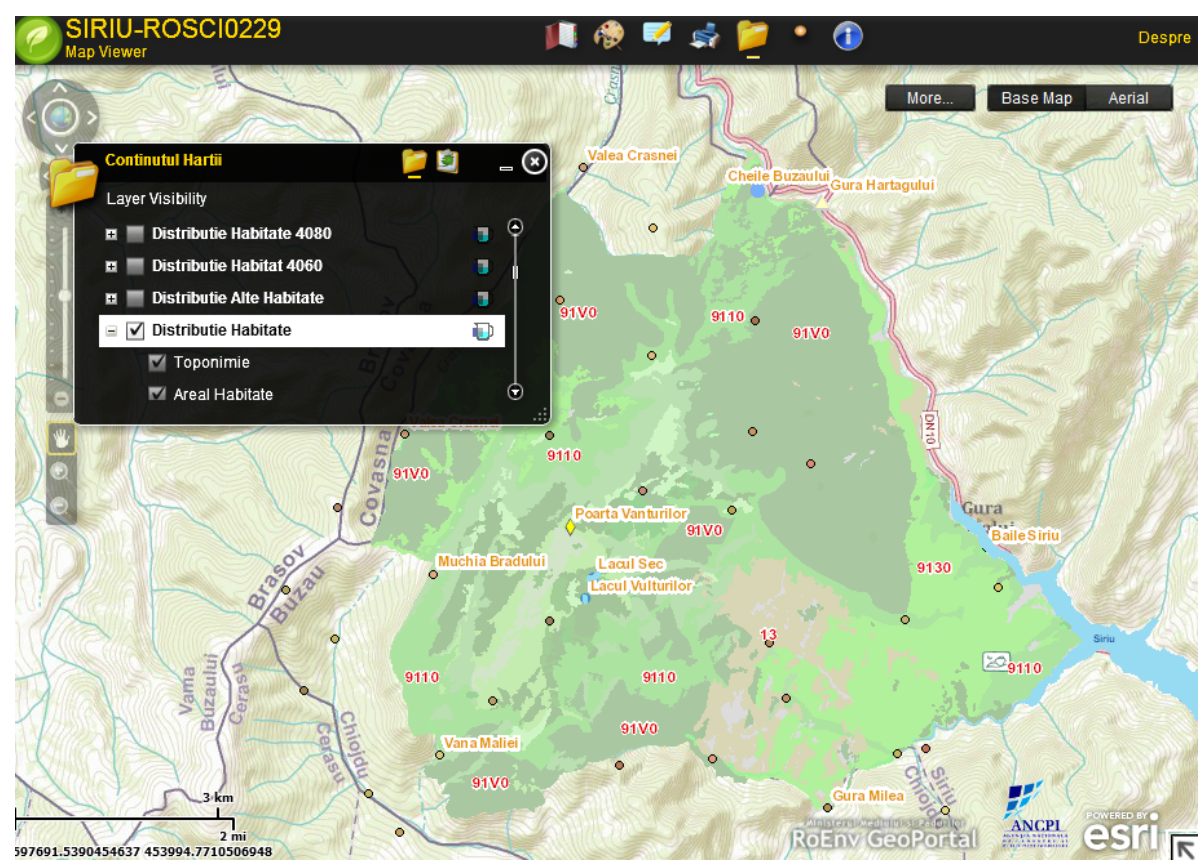

Fig. 4 ROSCI0229 Siriu Geoportal-operational layers.

assessment is provided the specific fito-population indices (dominance). In granting dominance indices it was taken into account the number of individuals and area occupied by these populations.

Another aspect of these measurements is related to the description of the potential impact which might be caused by the natural protected area site activities, such as: mining of aggregates, hydraulic works, construction, wastewater discharge, forestry and wood processing, fisheries, grazing, tourism activities, and so on, related to the species and habitats.

The geoportal offers a variety of geospatial web services from ArcGIS Online, ROEnv Geoportal application hosted by Ministry of Environment and Climate Changes and INIS GeoPortal [11] managed by the ANCPI (National Agency for Cadaster and Land Registration). All these available web map services can be mashed up and make it easier, quicker and cheaper for users to create their own GIS application related to biodiversity.

\subsection{Metadata Standards}

Metadata, or "data about data”, is the information that describes other data. Geospatial metadata refers to the information that describes geospatial data, Web services, or other geospatial resources. There is object-level metadata, which describes a single entity, and collection-level metadata, which describes a series or a group of entities [12].

Geospatial metadata published into the biodiversity geoportal catalog includes the following elements: resource identification, quality and validity, spatial reference, temporal and distribution information. Metadata is useful in data archiving, assessment, management, discovery, transfer and distribution to users. In the geoportal context, metadata has the following uses: discovery, evaluation and use of resources and the contract terms between the user and the publisher $[13,14]$.

Our biodiversity geoportal application with a centralized catalog has all its metadata records contained in one catalog, as presented in Fig. 5.

The Inspire implementing guidelines are based on EN ISO ${ }^{8} 19115$ (datasets) and EN ISO 19119 (services) for Commission Regulation (EC) No. 1205/2008 of 3 December 2008 implementing Directive 2007/2/EC of the European Parliament and of the Council as regards metadata (2010).

\footnotetext{
${ }^{8}$ ISO_-acronym for International Standards Organization.
} 


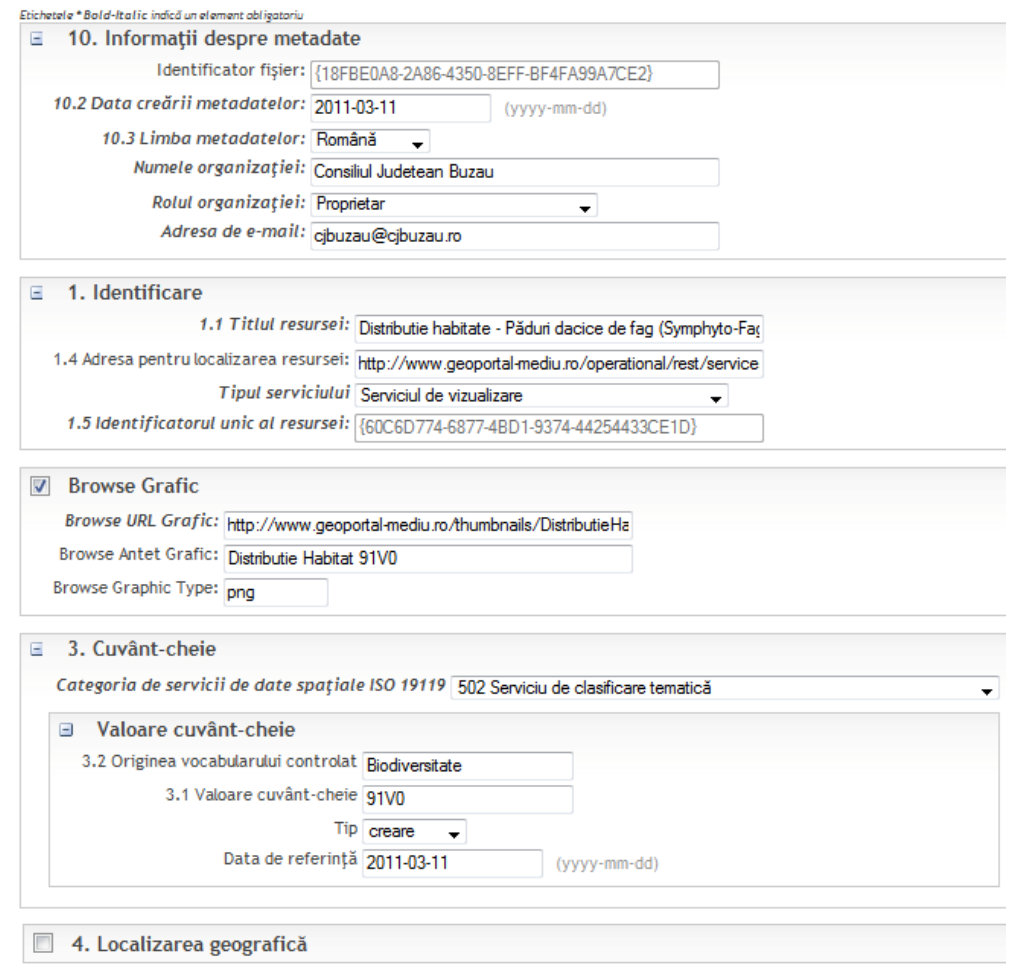

Fig. 5 ROSCI0229 Siriu Geoportal—metadata editor.

\subsection{Interoperability of Spatial Datasets and Services}

The ROSCI0229 Siriu biodiversity geoportal supports the following standards:

- Data models - Implementing Rules for the Annex I;

- Metadata standards-ISO 19115, ISO 19139, ISO 19119, Dublin Core, INSPIRE Profiles;

- Standard interfaces that enable users to discover resources through geoportal: OGC (Open Geospatial Consortium), Inc. for Web (CSW), CSW ISO AP, Inspire Discovery service, REST, OpenSearch;

- Interface standards - for integration with external map services such as: Esri ArcGIS Server; KML/KMZ; GeoRSS; OGC (Open Geospatial Consortium), Inc. WMS ${ }^{9}$, WFS ${ }^{10}$, and $\mathrm{WCS}^{11}$;

\footnotetext{
${ }^{9}$ WMS - acronym for Web Map Server, a set of interface specifications that provides uniform access by Web clients to maps rendered by map servers on the Internet. The WMS (Web Map Server) is the result of a collaborative effort assembled by the OGC (Open Geospatial Consortium), Inc..

${ }^{10}$ WFS-acronym for Web Feature Server, a set of interface specifications that standardizes data manipulation and map display on the Internet. The WFS (Web Feature Server) is the result of a collaborative effort assembled by the OGC (Open Geospatial Consortium), Inc.
}

- Interface standards-for catalog service harvesting such as: OGC (Open Geospatial Consortium), Inc. for Web (CSW), XML under WAF (Web-accessible folders), the Esri metadata service and the OAI (Open Archive Initiative).

\section{Next Steps}

The next research step of our biodiversity geoportal application is under development process to extend its capabilities to fully support the management planning process of all series of the Sectorial Operational Program "Environment" projects that are focused on inventorying and mapping natural habitats and wild species of community interest for the natural protected areas. Our best practices are open to new and innovative ideas in order to sustain this cyclical, iterative and developmental process of the management planning for the nature conservation

${ }^{11}$ WCS - acronym for Web Coverage Server, a set of interface specification for exchanging coverages over the Internet using a server. The WCS (Web Coverage Server) is the result of a collaborative effort assembled by the OGC (Open Geospatial Consortium), Inc.. 
sites.

By developing the management framework and awareness of owners and the main decision makers involved in land management, our project contributes also to the biodiversity and natural heritage protection and conservation by supporting the management of this protected area, including the implementation of Natura2000-the objective of the Priority Axis 4- "Implementation of adequate management systems for nature protection". Another issue of the next developments is addressed by the harmonization of key spatial data themes across Ministry of Environment and Climate Changes and NSDI (National Spatial Data Infrastructure) Council to support the European environmental policies.

\section{Conclusions}

During the next years, it will be important to establish a monitoring and reporting system for each protected area at local/regional level and it represents the most significant initiative Romania could undertake. It will create a more robust and comprehensive knowledge base for supporting effective planning and policy development, increased agency accountability and support for conservation. It will also provide the mechanism for the Ministry of Environment and Climate Changes to report and control local and regional agencies and the public on conservation performance and improvement in outcomes achieved.

The geospatial architecture framework and geoportal application facilitates information sharing and collaboration, including the bottom-up flow of information, open and interoperable Web services, mashups, cloud computing, and geobrowsers. Our proposed solution is encouraging stakeholders and biologists' community participation so together we can provide accurate and up-to-date information regarding biodiversity conservation status in each Romanian protected area. Our further work will focus on unifying all these local platform solutions and data in a more complex Biodiversity Monitoring and Reporting
System at the national level.

All of these technical advantages should also work in favor of our NSDI and provide support for building blocks of the European Commission's SEIS (shared environmental information system).

\section{Acknowledgments}

The authors wish to acknowledge the contributions and support from our scientific project experts-Multidimension and Ministry of Environment and Climate Changes and Buzau County Council. The project is under the Sectorial Operational Program Environment-Priority Axis 4: "Implementation of adequate management systems for nature protection”.

\section{References}

[1] Joint Nature Conservation Committee. 2014. "Common Standards Monitoring for Designated Sites.” Accessed December 5, 2014. http://jncc.defra.gov.uk/page-2217.

[2] European Environment Agency. 2014. EEA Reference Grid Samples for Projection ETRS89-LAEA 52N 10E. Accessed December 5, 2014. http://www.eea.europa.eu/data-and-maps/data/eea-referen ce-grids.

[3] Donita, N., Popescu, A., Pauca, M., Mihailescu, S., and Biris, I. 2005. Habitatele din Romania, Edit. Tehnica Silvica, Bucuresti, ISBN 973-96001-4-X.

Gafta, D., Mountford, O. 2008. Manual de interpretare a habitatelor Natura 2000 din Romania. Published under EuropeAid/121260/D/SV/RC, Edit. Rosprint, Cluj, ISBN 978-973-751-697-8.

[4] European Commission. 2014. "INSPIRE Data Specification for the Spatial Data Theme Protected Sites version 3.1.0.” Accessed December 5, 2014. http://inspire.ec.europa.eu/documents/Data_Specification s/INSPIRE_DataSpecification_PS_v3.1.pdf.

[5] European Environment Agency. 2014. "CORINE Biotypes - The Design, Compilation and Use of an Inventory of Sites of Major Importance for Nature Conservation in the European Community (version 2000).” Accessed December 5, 2014. http://www.eea.europa.eu/data-and-maps/data/corine-biot opes.

[6] Buzau County Council. 2014. "ROSCI0229 Biodiversity Geoportal Address.” Accessed December 5, 2014. http://www.geoportal-mediu.ro/geoportal/.

[7] Tait, M. G. 2005. "Implementing Geoportals: 
Applications of Distributed GIS.” Computers, Environment and Urban Systems Journal 29 (1): 33-47.

[8] Buzau County Council. 2014. "ROSCI0229 Biodiversity Geoportal-Website Component.” Accessed December 5, 2014. http://www.geoportal-mediu.ro/.

[9] Buzau County Council. 2014. "ROSCI0229 Biodiversity Geoportal Flex-based Map Viewer.” Accessed December 5, 2014. http://www.geoportal-mediu.ro/Siriu/viewer/.

[10] Buzau County Council. 2014. "ROSCI0229 Biodiversity Geoportal Distribution Maps.” Accessed December 5, 2014.

http://www.geoportal-mediu.ro/home/hartiDistributie.htm l.

[11] National Agency for Cadastre and Land Registration
(ANCPI). 2014. "Romanian INSPIRE Geoportal.” Accessed December 5, 2014.

http:/geoportal.ancpi.ro/geoportal/catalog/main/home.pa ge.

[12] Goodchild, M., and Zhou, J. 2003. "Finding Geographic Information: Collection-Level Metadata.” GeoInformatica 7 (2): 95-112.

[13] Longley, P. A., Goodchild, M. F., Maguire, D. J., and Rhind, D. W. 2005. Geographic Information Systems and Science. 2nd ed.. San Francisco: John Wiley \& Sons.

[14] Van Oosterom, P., and Zlatanova, S. 2008. Creating Spatial Information Infrastructures: Towards the Spatial Semantic Web. Boca Raton. Fla.: CRC Press, Taylor \& Francis Group. 